AIAA-99-2611

\title{
IN SPACE PROPULSION \\ ASSESSMENT PROCESSES AND CRITERIA FOR AFFORDABLE SYSTEMS
}

\author{
Russel Rhodes \\ NASA Kennedy Space Center \\ FL USA
}

\author{
Edgar Zapata \\ NASA Kennedy Space Center \\ FL USA
}

\begin{abstract}
"ABSTRACT
In a world of high launch costs to Low Earth Orbit (LEO), and of costs nearly twice as high to Geosynchronous Earth Orbit (GEO), it is clear that processes and criteria are required which will surface the path to greater affordability. Further, with propulsion systems making up a major part of the systems placed into multiple orbits, or beyond, it is clear that addressing propulsion systems for in-space propulsion (ISP) is a key part to breaking the barriers to affordable systems. While multitudes of Earth to Orbit transportation system efforts focus on reduced costs, the often neglected costs and related interactions of the inspace system equally require improvements that will enable broad end-to end customer affordability.

It is the objective of this paper to describe a process used by the Space Propulsion Synergy Team (SPST) InSpace Propulsion Task Force in the development of technology evaluation criteria for future in-space propulsion systems. The method used is a structured, traceable process which surfaces key drivers for the development of affordable systems responsive to customer needs. The experience and knowledge of diverse, relevant team members is a cornerstone of the process. Multiple applications, reusable to expendable systems, in Earth orbit, solar/planetary orbit or beyond, such as interstellar, have all been considered as options within the process. Further, the results of the process are presented in particular as relates to the cross-cutting needs of diverse customers for future in-space operations.
\end{abstract}

\footnotetext{
* Copyright $(\odot) 1999$ by the American Institute of Aeronautics and Astronautics, Inc. No copyright is asserted in the United States under Title 17, U.S. Code. The U.S. Government has a royalty-free license to exercise all rights under the copyright claimed herein for Governmental purposes. All other rights are reserved by the copyright owner.
}

\section{INTRODUCTION - WHY THE NEED?}

\section{Weight?}

In considering in-space propulsion one possible discriminator is launched mass. By one measure, weight, for every pound of launched mass about half ${ }^{1}$ on average of that yearly mass is due to in-space propulsion. Further insight into the interactions of costs, technology, designs, and approaches, of such a major systems contribution requires a methodical approach to drive out the major barriers to growth in the deployment of these systems.

\section{$\underline{\text { Interfaces? }}$}

Taking as one example a unique capability such as that of Shuttle, a review of data indicates major costs incurred due to payload impacts (Table 1.0). Upgrade efforts ${ }^{2}$ have studied the effect of new approaches, such as standardized interfaces and standard racks and carriers, as shown in Figure 1.0. The offline processing aspects and easier integration into the transportation system have been criteria of emphasis. Cost savings of up to $10,000 \mathrm{mhrs}$ have been identified.

Expendable systems with custom payload intensive operations, on the ground or for in-space operations, could also be as positively affected by more standardization.

\begin{tabular}{|l|c|}
\hline \multicolumn{1}{|c|}{ Orbiter Processing Task } & MHrs \\
\hline Payload Install \& Launch Verify & $\sim 7800$ \\
\hline Payload Remove Preps & $\sim 15000$ \\
\hline Mission Unique Payload & $\sim 26000$ \\
\hline
\end{tabular}

Table 1.0 Shuttle Payload Processing Impacts, one part of a much larger process and much broader cost areas. 
The need to reduce costs may drive to addressing an issue such as standardization of interfaces in an attempt to gain the benefits of learning curve, or simplification.

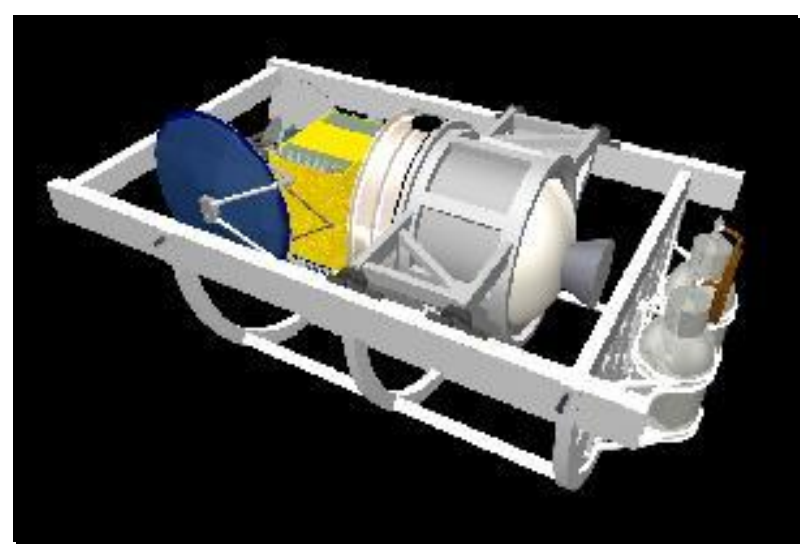

Figure 1.0 Standardized Payload Carrier for Shuttle Deployed Payloads.

\section{Operations Insights?}

Still other studies ${ }^{3}$ have categorized broad, generic drivers affecting payload or cargo costs at the launch site, such as the impacts of complex propulsion systems requiring multiple support systems and delaying the overall transportation systems through-put. Contrasting such systems is shown in Figure 2.0. Study variables identified broader impacts of payload interactions and costs which ultimately spanned the preparation of the payload, it's ground infrastructure, and it's more visible operational impacts once in use in orbit or beyond.

\section{Future Challenges?}

While the experience to date has been that of managing flights on the ground counted below one hundred per year worldwide, but growing, and of managing assets in-space numbering in the hundreds, many challenges have been identified that will stretch the bounds of current thinking.

Space Solar Power is one such possibility. For the objective of delivering power to the public at about 5 cents a kilowatt-hour, and of doing so cleanly, without the environmental impacts of hydrocarbon fuel usage, a mass to orbit per year of 15,561 metric tons is required $^{4}$. This mass of nearly 35 million pounds per year must (1) be delivered to LEO at very low hundreds of dollars a pound rates for the economic objectives such as investment return and power price to close, and (2) must be taken beyond LEO to GEO, the final operational sun-tower sites. Spacetugs and in-orbit systems automatically taking the portions of the suntower segments from LEO to GEO are crucial to enabling such ambitious endeavors even assuming the Earth to orbit delivery systems are developed to perform the duties to LEO at $\$ 100 / \mathrm{lb}$.

The sun-tower segments, a rough concept version of which is shown in ${ }^{4}$ Figure 3.0, may have to be cookiecutter standardized and extremely reliable by any comparison to today's systems, even by comparison to large constellations being conceived such as Teledesics.

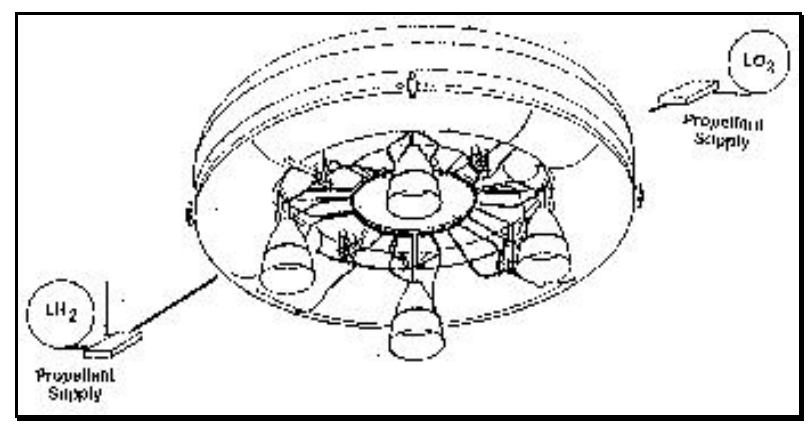

Figure 2.0 Integrated Modular Propulsion System for ${ }^{3}$ OEPSS Study, circa 1993. Addressing broad impacts of payload to ground interactions, affecting in-flight/inspace affordability as well. Addressed attributes of systems integration, fluid transfer in space, fluids in space, in-space assembly, hardware dependability, fault tolerance, and propellant management issues among others.

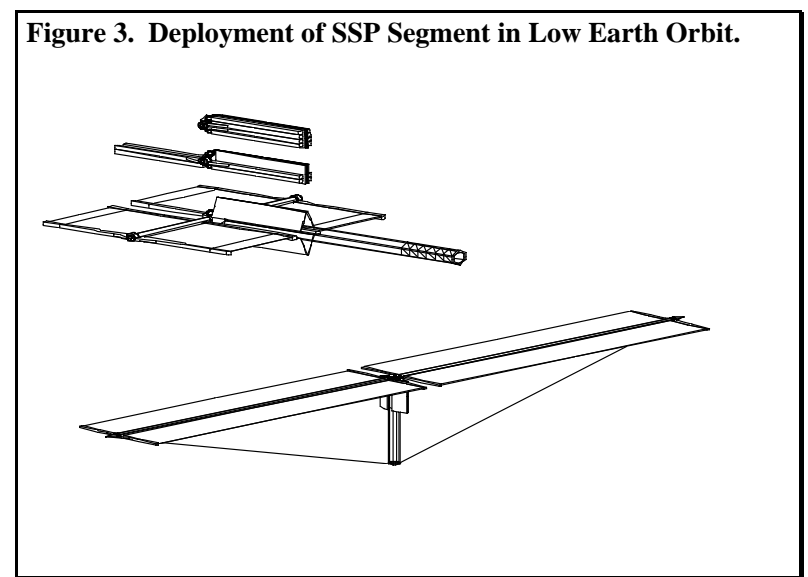

Figure 3.0 Space Solar Power segment; deployment of one of hundreds of segments that would be required to construct one Suntower. Automated assembly, after transfer from LEO to GEO, would be required as the tower builds itself. NASA Space Solar Power Study and Boeing Company concept. 


\section{The Need - Structured Processes}

In keeping with the objective of radically reducing the cost and operations time for new space missions and payloads at orbits higher than parking LEO it becomes apparent that a process for surfacing criteria for improving in-space propulsion systems is required.

\section{SPACE PROPULSION SYNERGY TEAM}

The Space Propulsion Synergy Team (SPST) is a broad based group of diverse individuals from NASA, Department of Defense, industry and academia, which has addressed in ${ }^{5}$ past and current efforts the direction of future space transportation systems and technology. The involvement of many key backgrounds and areas of insight in the SPST has been an integral part of understanding and prioritizing key attributes for improvement.

Members of the In-Space Propulsion Task Force Assessment Process / Criteria Sub-Team (Figure 4.0) bring to the table the necessary experience that allows knowledge and insight to properly complement information and data. This knowledge base sets the foundation for the rest of the process.

At the outset of any such process objectives and roles are clarified that set the tone for later work. The objective of the SPST Task Force on in-space propulsion is to develop plans, harvest good ideas and approaches, recommend technology development, advancement and subsequent infusion to applications, and by doing so, assist to radically reduce cost (order of magnitude, minimum) and operations cycle time for all new space missions requiring multiple in-space functions and operations at orbits higher than minimum Earth parking LEO.

Within this context the sub-team on assessment processes and criteria was established. The teams purpose was to develop technology evaluation criteria and a process that would assist in defining future inspace propulsion needs in the near and far term.

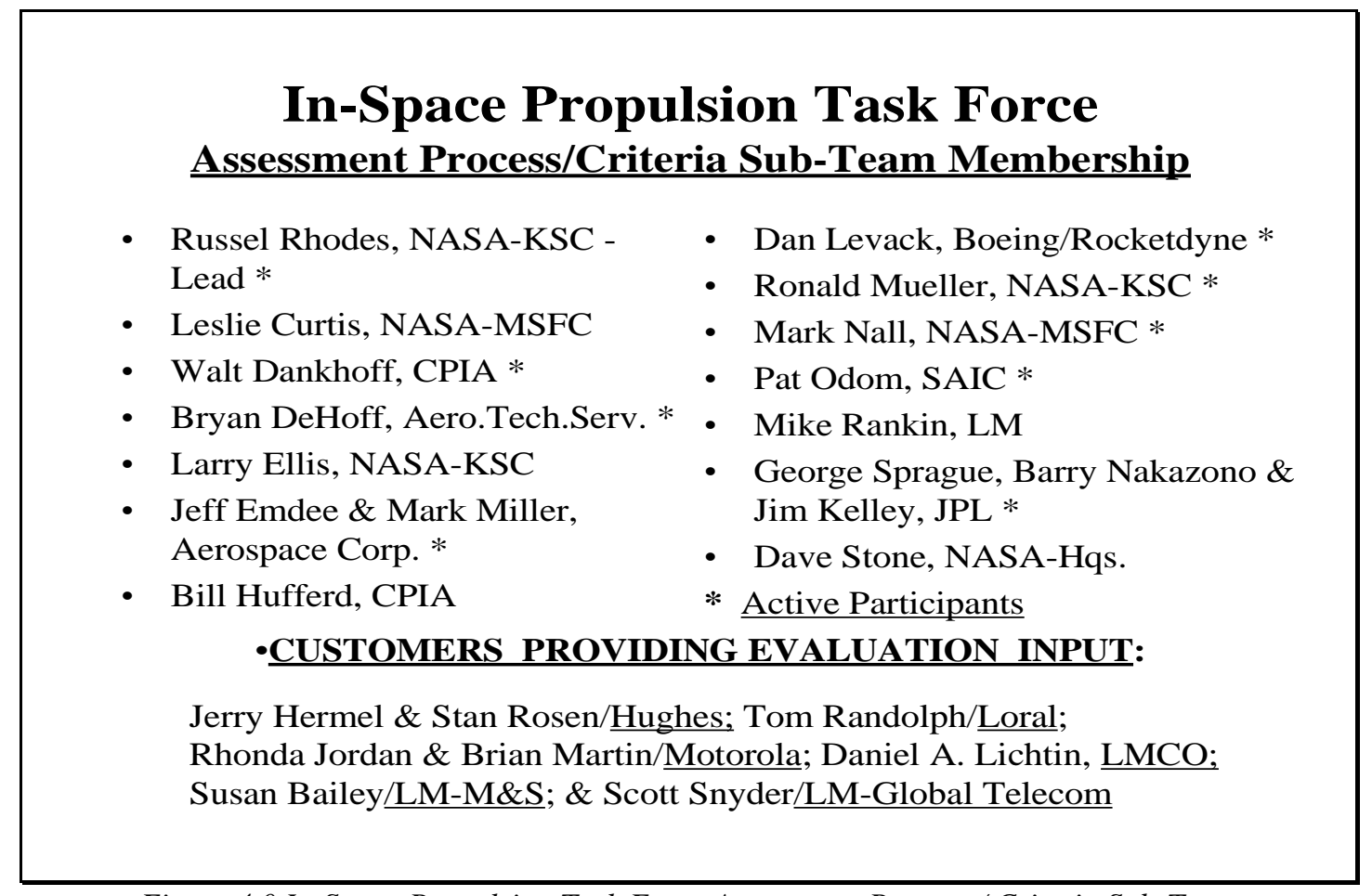

Figure 4.0 In-Space Propulsion Task Force Assessment Process / Criteria Sub-Team

\section{THE PROCESS}

Determining a process for developing in-space propulsion evaluation criteria need not start in a vacuum. Multiple processes such as brainstorming, analytic hierarchy process (AHP) and cross correlation matrices already exist. They are accepted tools used in such early, conceptual exercises geared at establishing significant variables to be later considered. In this particular case the variables are criteria that drive affordability of in-space propulsion systems across the life cycle of the product. The customer, represented 
throughout the process, is a heavy influence in both AHP and cross correlation matrix type processes.

The SPST has applied such processes to great success in previous work, such as in the 1995-1997 NASA Highly Reusable Space Transportation (HRST) ${ }^{6}$ study. One task performed by the SPST within the HRST study, was the identification of top-level design and programmatic criteria that would vastly improve Earth to orbit space transportation if applied to future concepts, flight and ground. Within a scenario of limited resources and a highly competitive world, having a sharp focus on key affordability drivers for future spaceliners capable of offering services at $\$ 100 /$ lb for payload can make a difference between very successful enterprises and merely diffused efforts.

In this task for in-space propulsion both AHP and cross correlation matrices were relied on with the greater emphasis on the later. Use of a cross correlation set of matrices is essentially a process of consistency, quantification and prioritization. Without consistency later results may surface inappropriate results with no clear message or communication of significant factors. Without being quantifiable a designer, creator, or investor in a product would have only vague senses of influence relationships among factors to be considered. Finally, prioritizing visualizes the factors that require most attention in a product development so as to achieve a successful product that satisfies customers and grows opportunities.

A typical criteria development process representing the basics of an objective driven, flow-down process is shown in Figure 5.0. For the ISP work the attributes are the more fuzzy, qualitative desires wanted in space systems. These are the oft expressed "low cost", "flexibility" or "operability" as examples. The forcing function of a process such as that used by the ISP task force is to go beyond these to criteria that are measurable and therefore can be acted on to alter, shape and define future products. Those products, in this case, are primarily technologies and approaches that will be invested in by NASA and industry. Poor product planning unable to respond to these criteria is unlikely to satisfy future needs and customers.

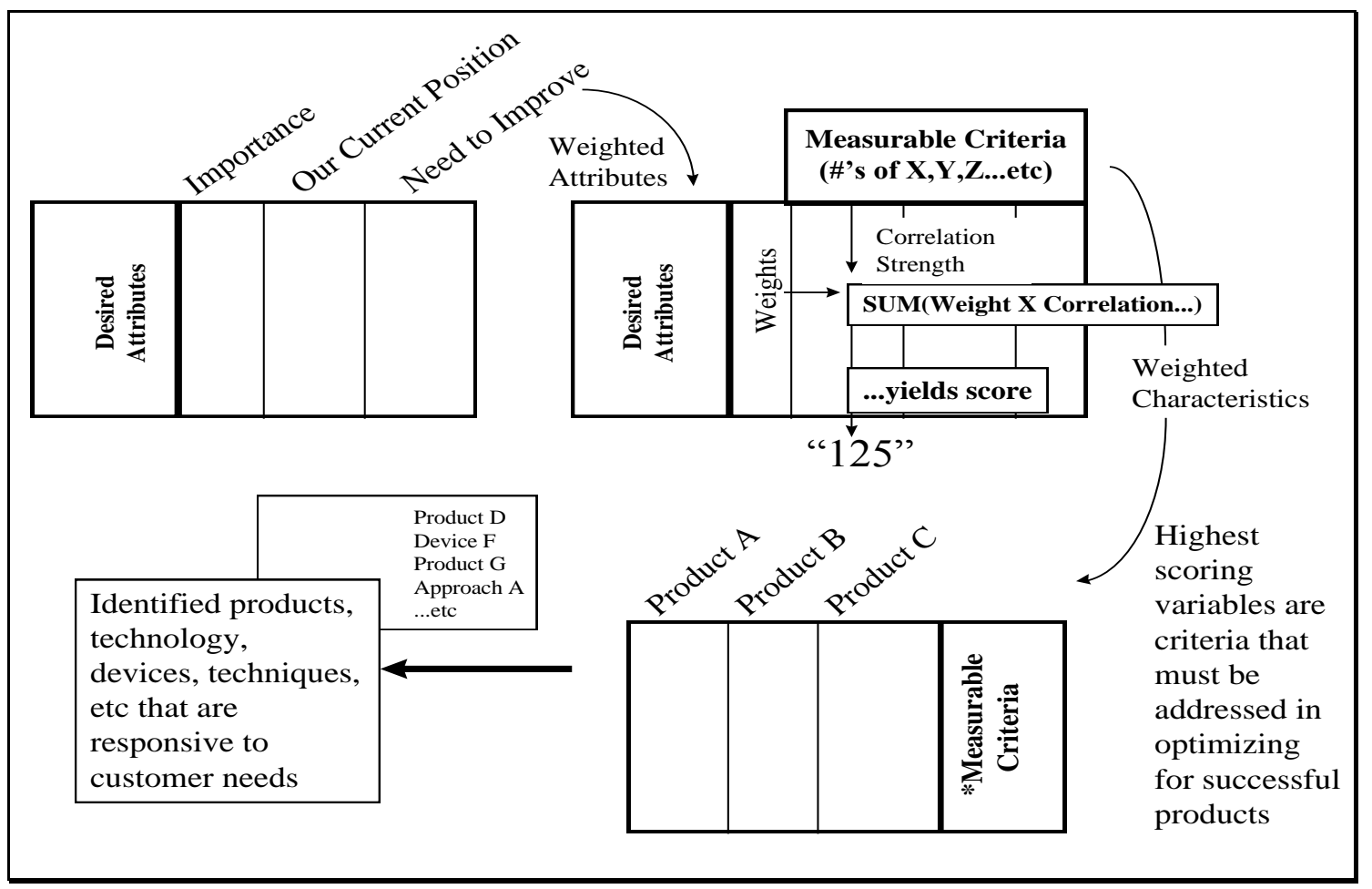

Figure 5.0 Flow-down from objectives to attributes to criteria, as applied to In-Space Propulsion by the SPST. *The criteria as shown, in the hybrid process explained ahead, are substituted with AHP and attributes. 


\section{ATTRIBUTES AND CRITERIA, A MUCH IMPROVED COST AND BENEFIT $\underline{\text { APPROACH }}$}

The prior use of attributes and criteria follows a dual path approach. One is the exercise as run for the technical or benefit criteria. Such criteria that result may be considered in the classic sense of "benefit" in a cost/benefit analysis. A second exercise is run taking into account issues addressing the difficulty of an enterprise, such as cost, risk of not succeeding, and other up-front factors. The later programmatic criteria, as referred to in the ISP task, is the "cost" considered in the classic sense of a cost/benefit analysis.

The separation is a requirement for a 2-D buildup as shown in Figure 6.0.

The 2-D buildup has one characteristic that is crucial in such an exercise. It is visual. The visualization of data results in a more readily understood and assessed situation of the assets deployed in the field. Are assets in need of support that can move them to the right? Are resources being spent on assets that will not forge into the right areas?

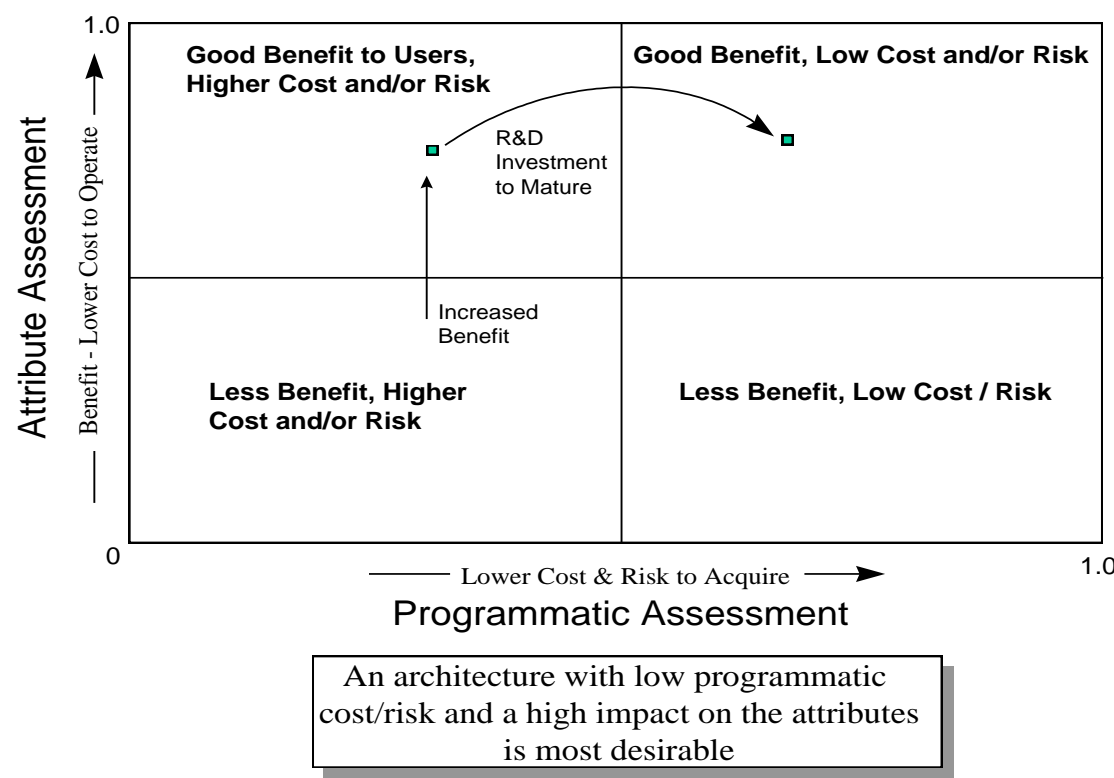

Figure 6.0 The 2-D Buildup of Benefit vs. Cost Type Criteria. The visual layout preserves the necessary distinction that identifies areas that may not be mature, but would provide high benefit if invested in and moved to the right. Also, items that fall into low benefit categories, even if low risk or cost, are also highlighted. Ready items, in the top right, when identified, are the most beneficial.

\section{ATTRIBUTES AND CRITERIA FOR IN- SPACE PROPULSION}

The attributes used in the ISP process and criteria task force are outlined in Figure 7.0.

It can be seen that the attributes are all-encompassing. In defining attributes the qualities have not yet been screened or prioritized. At this stage the goal is completeness and broadness of the areas being considered. Questions of improvement and emphasis are left to the process to naturally surface and make clear and it is not at the attribute level that major variables, such as those to consider in a design space, are identified. This is merely square one on the path.

Following the identification of attributes a customer weighting process is employed. The process (also outlined in Figure 5.0 previously) takes into account not just importance, but need to improve. In this respect there is a slight variation from AHP as it is often used which only accounts for importance in the eyes of the customer.

The eventual, prioritized attributes surfaced in the ISP process and criteria team included a strong emphasis on recurring factors (in top-down order) such as operations and support costs, ease of supportability, ease of 
vehicle/system integration, avoiding corrective action, automated system health verification, minimized cost impact on launch system, vehicle system replacement, launch on demand, etc.

The next step in the process was the definition of criteria. Here, multiple differing situations needed to be taken into account.
For example, a customer situation and by inference the degree to which criteria influence an attribute, may vary from a customer that is considering an Earth orbit application, as compared to another customer who has a planetary mission.

A brief outline of the in-space transportation systems applications considered is shown in Table 2.0.

\section{The Attributes of a Space Transportation System}

\begin{tabular}{l|c}
\hline Affordable / Low Life Cycle Cost & \\
Min. Cost Impact on Launch Sys. & Responsive \\
Low Recurring Cost & Flexible \\
Low Cost Sensitivity to Flight Growth & Capacity \\
Operation and Support & Operable \\
Initial Acquisition & Auto. Sys. Health Verification \\
Vehicle/System Replacement & Auto. Sys. Corrective Action \\
Dependable & Ease of Vehicle/System Integration \\
Highly Reliable & Maintainable \\
Intact Vehicle Recovery & Simple \\
Mission Success & Launch on Demand \\
Operate on Command & Easily Supportable \\
Robustness & Resiliency \\
Environmental Compatibility & Safety \\
Minimum Impact on Space Environ. & Vehicle Safety \\
Minimum Effect on Atmosphere & Personnel Safety \\
Minimum Impact all Sites & Public Safety \\
Public Support & Equipment and Facility Safety \\
Benefit GNP & \\
Social Perception & \\
\hline \hline During the Technology R\&D Phase: & During the Program Acquisition Phase: \\
\hline Affordable / Low Life Cycle Cost & \\
Cost to Develop & Affordable / Low Life Cycle Cost \\
Benefit Focused & Cost to Acquire \\
Schedule & Schedule \\
Risk & Risk \\
Dual Use Potential & Technology Options \\
\hline & Investor Incentive \\
\hline
\end{tabular}
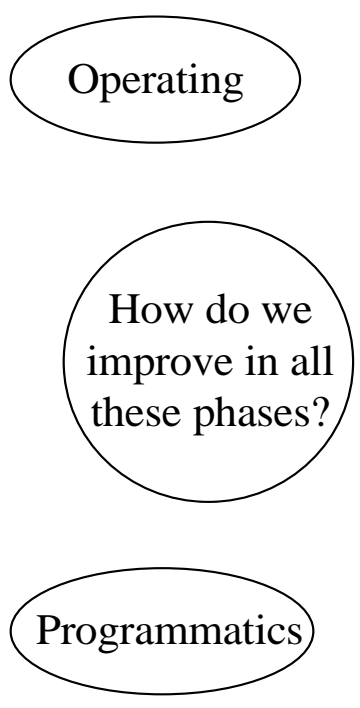

Figure 7.0 Attributes for the ISP Process and Criteria task force. These attributes were weighted in multiple ways, for different applications, such as Earth, planetary and beyond, as well as for diverse methods, such as expendables, reusable ground based, reusable space based and others. The process was repeated for each commercial customer participation.

All of these application options were considered in the ISP process and criteria development team.

Definitions were documented and traceability of the process was preserved to avoid any later confusion in the assignment or meaning or terms such as the applications as well as the meaning of attributes or criteria and these documents are available on request.

The process of surfacing criteria could then begin. Over a series of face-to-face discussions as well as remote conferencing a set of consensus values arises. Of greater value, the process serves to bring to the table viewpoints, data, supporting information and insight all of which is shared and feeds into the process leading in such exercises to a process that is equally as valuable as the product (sets of evaluation criteria) that is the endpoint. 


\section{$\underline{\text { Analytic Hierarchy Process (AHP) }}$}

In the interest a more streamlined process, an AHP analysis was performed in complement to the previously described cross correlation matrix process. Much of the matrix process having been based on previous work in the field it was desired to understand any inconsistencies that might occur in the process.

For this, team members (SAIC) performed a matrix results to AHP correlation and provided study results.
The data clearly showed very strong correlation between data generated by adapting the AHP model to the previous matrix-based approach. It was determined that an approach highlighting the values of both processes would be tried. The cross correlation matrix method would be used to generate and weight attributes and measurable criteria, and then, AHP would be used, with those weights and criteria, to perform prioritization of candidate technologies. This represents a hybrid approach which is acceptable as a valid and a coherent methodology.

\section{Reusable Systems:}

Reusable Ground Based: The transportation system (vehicle) is capable of performing repetitive in-space operations. It returns to ground base after completing each mission for preparation and servicing (including any required maintenance) for the next flight mission. Its range of service is both Earth Orbit and Planetary Orbits.

Reusable Space Based: The transportation system (vehicle) is capable of performing repetitive in-space operations. After completing its mission (delivery of its payload) it remains in earth orbit; and is serviced for the in-space operation by another space transportation system launched from the ground. Its range of service is both Earth Orbit and Planetary Orbits.

Earth Self Re-Entry: The space based vehicle has the capability of re-entry to earth upon command for depot maintenance or for cargo delivery to earth.

Orbit Capture and Return: The space based vehicle must be captured by another space transportation system vehicle launched from earth for this purpose. It is then returned to earth aboard the capture vehicle, which has reentry capability. The purpose of earth re-turn trip would be primarily depot maintenance of the in-space transportation system.

Expendable Systems: The in-space transportation system is expended following the completion of its mission. The propulsion systems of satellites are also considered in this class of application. The range of service for this class is considered unlimited, but, defined as follows:

Earth Orbit: Any one of several earth orbital transfers, including change of orbital diameter and inclination. For example, transfer from Leo to Geo.

Solar Orbit: Any one of several orbital transfers/trajectories required for a Lunar or Planetary mission/missions.

Beyond Solar: Any of several missions that require transportation outside the Solar system (Interstellar).

Table 2.0 ISP Transportation Systems Options

\section{CRITERIA DEVELOPMENT}

Based on the attributes previously determined, a series of criteria were generated (randomly) that were (a) related to the attributes, (b) could be more detailed, or measurable and (c) leveraged off of previous work adding the necessary attributes and criteria for in-space propulsion. This drew on the team members diverse background fusing knowledge bases with experience and diverse sources of information relevant to in-space issues.

The result was a set of criteria in matrices that could then be correlated to the attributes. Based on previous attribute weights determined for customers a series of prioritized criteria for reusable or expendable approaches, for different applications, Earth, planetary or beyond, were calculated (attribute weights multiplied by criteria relations, summed across attributes). 
Given the large scope, number and size of the matrices it is beyond the scope of this paper to include these here. The results for the different scenarios did show a remarkable degree of similarity, as will be discussed ahead.

\section{RESULTS OF THE PROCESS}

Multiple areas of emphasis have been previously outlined as expressed by the user community in addressing in-space propulsion. These include weight concerns, interface standardization, and future systems requiring rapid, almost "cookie-cutter" throughput.

Criteria surfacing as key in the ISP process included:

a) \# of different propulsion sys (-)

b) \# of hands on activities required (-)

c) \# of active sys. required to maintain safe veh. (-)

d) \# of toxic fluids (-)

e) \# of in-space support sys. required for propulsion sys. (-)

f) \# of unique stages (flight \& grd.) (-)

g) \# of systems with BIT BITE (+)

h) \# components with demonstrated hi reliability (+)

i) \# of active components required to function including flight operations (-) j) \# of potential leakage/connection sources (-)

k) \# of active on-board space sys. req'd for prop. (-)

1) \# of active ground sys. required for servicing(-)

m) \# of confined spaces on vehicle (-)

n) $\%$ of propulsion sys. automated (+)

o) On-board propellant storage \& management difficulty in space (-)

p) System margin (+)

q) \# of sys. requiring monitoring due to hazards(-)

r) Hrs. for turnaround (bet. Launches or commit to new mission) (-)

s) \# of purges req'd (flight \& ground) (-)

t) Minimum impulse bit (+)

u) ISP propellant transfer operation difficulty (resupply) (-)

v) \# of checkouts required (-)

w) \# of inspection points (-)

x) Technology readiness levels (+)

y) \# of different fluids in system (-)

z) $\%$ of propulsion subsystems monitored to change from hazard to safe $(+)$

aa) \# of pollutive or toxic materials (-)

bb) \# of expendables (fluid, parts, software) (-)

cc) Mass Fraction required (-)

dd) \# of propulsion sub-sys. with fault tolerance (+)

ee) \# of engines (-)

ff) \# of umbs. req'd to Launch Veh ( - )

gg) $* *$ PLUS 45 MORE CRITERIA**

\section{In-Space Propulsion Technology Design Criteria Applications Relationship For Earth Orbit}

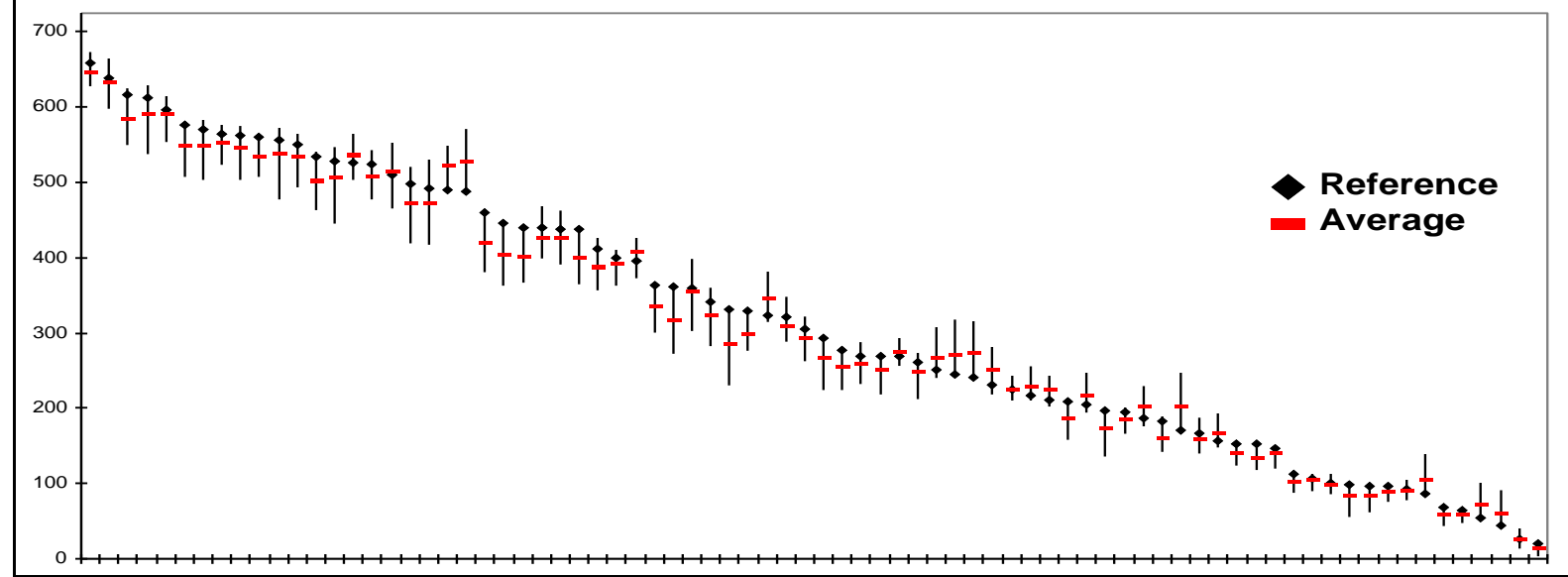

Figure 8.0 One axis of the process, the benefit aspect, and criteria rankings in order. Multiple cases are included as Hi-Lo indications here, such as expendables, ground based or space based reusables, and so-forth. The reference case is a ground based reusable. 
Of note, these criteria "moved" from application to application (earth, planetary, beyond) and from type to type (reusable, expendable) but the general areas in which criteria fell tended to be grouped and similar (top of list, middle of list, bottom of list).

A summary for one application is graphed in Fig. 8.0.

The graph as shown indicates the variation from customer to customer and for different applications. For example, one may have been a customer from an expendable perspective, another from a ground based reusable perspective, both assessing in terms of the Earth (LEO to GEO) application.

A simple average is included in the previous graph only for visual purposes. Team consensus driving processes were actually used to arrive at individual scoring results. The "Reference" referred to is just one case, for Figure 8.0 "ground based reusable", around which the criteria are paretoed. Other cases, such as expendable or space-based reusable, (as outlined in Table 1.0) are represented within the length of the Hi-Lo graph.

For programmatic issues similar graphs and analysis were performed.

The programmatic issues capture the $2^{\text {nd }}$ Axis of any assessment process, generally understood as the "cost" to get to an objective be it in dollars, time, or risk.

These program issues are shown in Figure 9.0.

\section{In-Space Propulsion Technology Programmatic Criteria Applications Relationship For Earth Orbit - R\&D Phase}

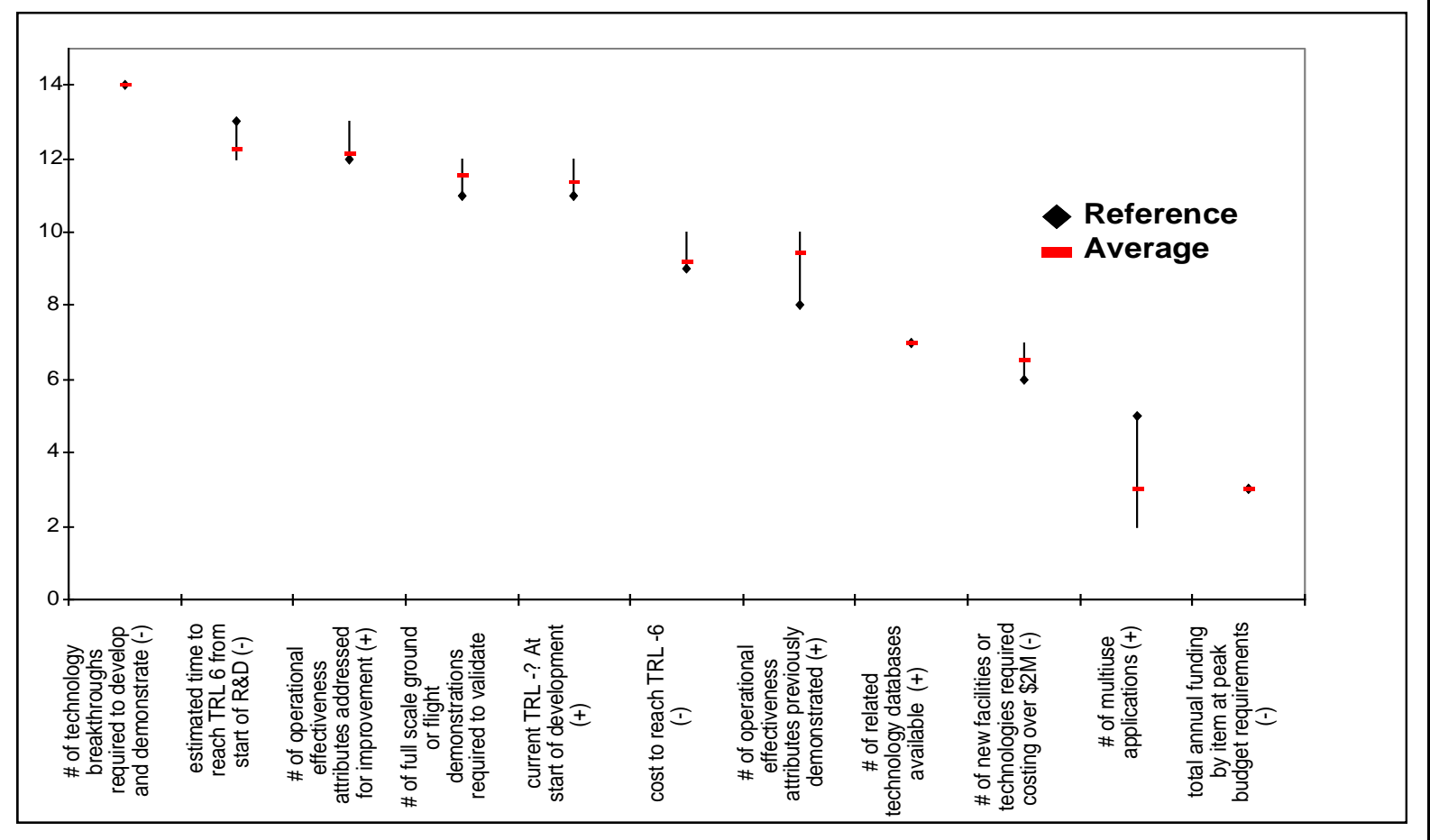

Figure 9.0 The second axis of the process, the programmatic aspect, and criteria rankings in order. Multiple cases are included as Hi-Lo indications here, such as expendables, ground based or space based reusables, and so-forth. The reference case is a ground based reusable. The particular program phase is the research and development (R\&D) phase.

In the interest of a breakout that clearly delineated between the R\&D aspects of a project and the acquisition aspect the programmatic issues were defined for each of these phases separately.
Whereas Figure 9.0 addressed the R\&D phase, Figure 10.0 addresses the criteria as seen at the program acquisition phase. 


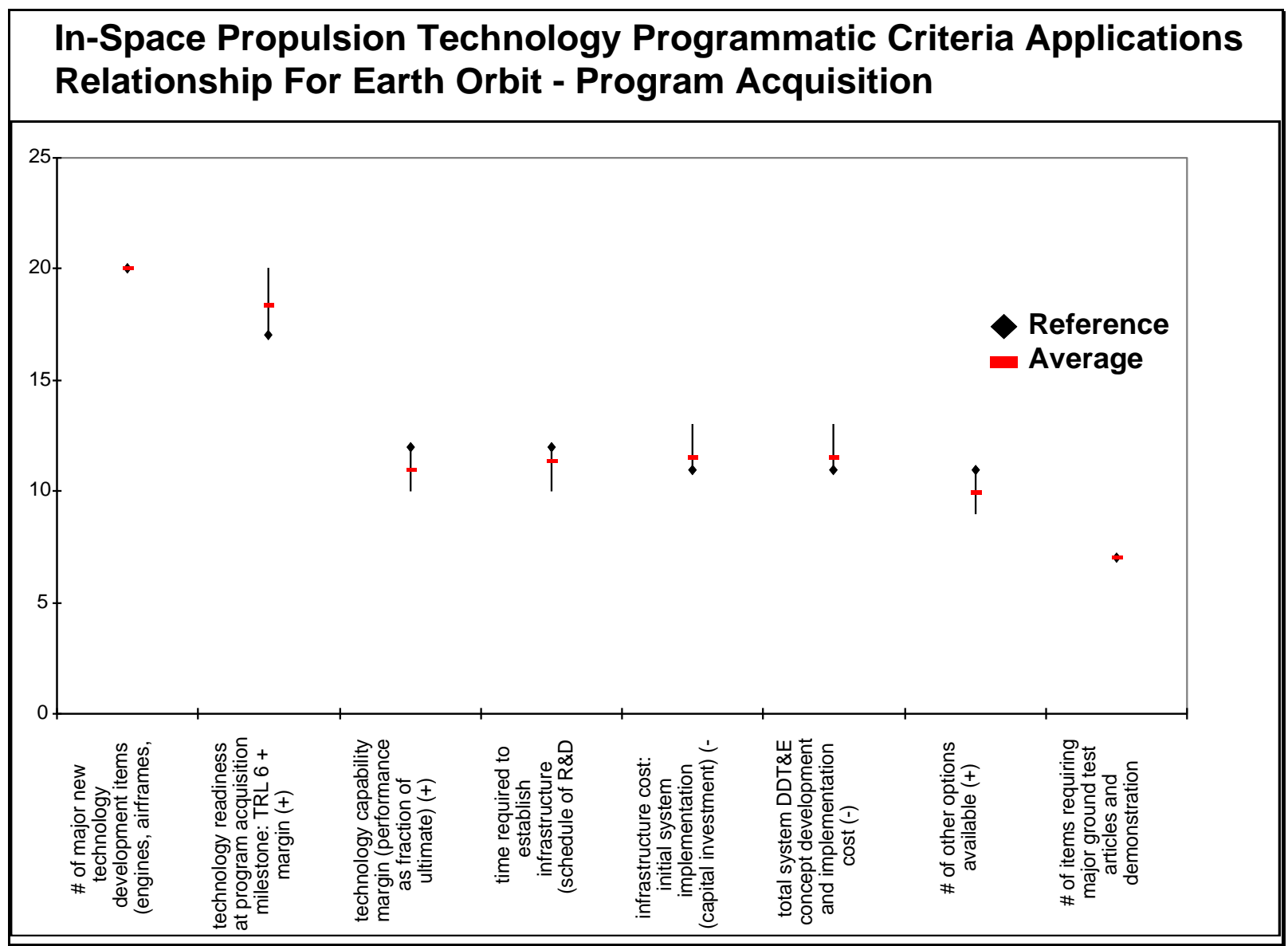

Figure 10.0 The second axis of the process, the programmatic aspect, and criteria rankings in order. Multiple cases are included as Hi-Lo indications here, such as expendables, ground based or space based reusables, and so-forth. The reference case is a ground based reusable. The particular program phase is the program acquisition phase.

\section{SUMMARY AND REVIEW OF RESULTS}

\section{Benefit/Technical/Design Criteria}

The criteria outlined in Figure 8.0, and listed alongside, present a macro-technical set of variables, in order of impact, in relation to the attributes, mostly about affordability, for in-space propulsion. As such they are the identified variables that must be considered and weighted more heavily in trade studies, for consideration of sensitivities, and as part of any optimization process attempting to juggle performance objectives with recurring cost objectives.

The attributes set the stage for considering "what is needed to improve" and the criteria have set the stage for defining "how do we get there". Within this broad, more far term context it is not surprising that in considering the many design variables in relation to affordability type attributes, that issues commonly seen as system life cycle cost drivers (such as weight), may not necessarily surface.

Multiple of the criteria, such as the need for more integrated systems (as expressed in the criteria "\#of different propulsion systems") may be synergistic with reduced weight. Yet the criteria as defined and explored offer a feedback process to any design process that more clearly defines tactics for improvement.

Criteria avenues also surface in groups which are interrelated, such as to reliability, which offer multiple paths to improvement (such as reduced parts count, stages, active components, leakage sources, propellant storage management and difficulty in space, margin, purges, etc).

It becomes clearer from the process highlights that vastly simplified systems, such as represented in Figure 2.0 , represent a mostly un-explored path offering great potential for improvements in in-space propulsion systems overall affordability. 


\section{$\underline{\text { Program/Cost/Risk Criteria }}$}

The criteria outlined in Figures 9.0 and 10.0 present a broad set of criteria focused on the non-recurring aspects of life cycle costs. It can be seen that the R\&D phase is most sensitive to needed breakthroughs, time to reach an "out of the test-bed" maturity, and any full scale hardware demonstrations required. It is less sensitive (or should be) to peak funding by items. The program acquisition phase also highlights 2 major criteria, having mature technology at go-ahead, and the number of new technology items being acquired.

\section{ISP - POSSIBLE FUTURE AVENUES}

In late April 1999, a workshop addressing future technologies will build on the processes here described. Technology candidates will be considered and the criteria outlined previously will be applied in a structured process. In this way more light will be shed on needed future investments which may be made by NASA or industry decision makers.

Other future possibilities include a "Guide" created by the SPST which compiles information, insight, data, and knowledge in greater detail as relates to in-space propulsion. Such a ${ }^{7}$ product was created in 1999 for the subject of Earth to-orbit transportation (leading to the realization that the in-space piece required addressing as has been outlined here.) Such a guide proves a useful tool to bring together data and distill the information into a structured, useful document and reference.

Further work would create quantitative models based on the inter-relationships of the criteria established here. Such work has been performed in the past on the Earthto-Orbit part of a space transport. Projections to assess the degree to which an objective is likely to be achieved may then be performed.

\section{CONCLUSIONS}

Multiple criteria have here been arrived at for in-space propulsion through a structured, traceable process that relies on information complementing a diverse experience/knowledge base. The life cycle perspective has been divided into recurring and non-recurring factors for ease of understanding system drivers. Multiple criteria not traditionally considered have been surfaced as requiring addressing by the design and technical communities in seeking ever better ways to grow the applications requiring affordable access to inspace propulsion.

\section{ACKNOWLEDGMENTS}

The authors gratefully acknowledge the work and support in this project of the dedicated, dependable, active In-Space Propulsion task force sub-team members of the SPST, and also the inputs provided by the customer participants.

\section{REFERENCES}

1. Sackheim, R.L., Jones, Lee W., (1997) "Space Propulsion synergy Group (SPSG) Upper Stage Assessment," AIAA Paper 97-2982.

2. NASA (1998) "Space Shuttle Upgrades PRCB, Standard Payload Carrier Study," KSC Advanced Development and Shuttle Upgrades.

3. NASA (1993) "OEPSS Operationally Efficient Propulsion System Study, Final Briefing/Report with Additional Backup Material," NAS10-11568, Rocketdyne Division/Rockwell International.

4. NASA (1998) "Space Solar Power Concept Definition Study," Early, Preliminary, Partial Report, Joe Howell, NASA MSFC, October 19, 1998, Rev. A. Boeing Architecture Study.

5. Aerospace America (1997) "Defining the Parameters for Affordable Space Transportation," Zapata, E., and Dankhoff, W., November 1997.

6. NASA (1998) "Final Report, An Operational Assessment of Concepts and Technologies for Highly Reusable Space Transportation, Executive Summary and Full Report," by the Highly Reusable Space Transportation Study, Integration Task Force, Operations, Nov. 1998. Also at: http://www.ksc.nasa.gov/shuttle/nexgen/rlvhp.htm

7. SPST (1997) "A Guide for the Design of Highly Reusable Space Transportation,” August 29, 1997. Available at: www.ksc.nasa.gov/shuttle/nexgen/ rlvgide.htm 